\title{
T-cell activation-inhibitory assay: a proposed novel method for screening ca- loric restriction mimetics
}

\author{
Shu Iura ${ }^{1}$, Yuusei Osima ${ }^{1}$, Yoshiaki Amakura ${ }^{2}$, Morio Yoshimura ${ }^{2}$, Atsushi Sawamoto $^{1}$, Satoshi Okuyama ${ }^{1}$, \\ Yoshiko FuruKawA ${ }^{1}$, and Mitsunari NAKAJIMA ${ }^{1}$ \\ ${ }^{1}$ Department of Pharmaceutical Pharmacology, College of Pharmaceutical Sciences, Matsuyama University, 4-2 Bunkyo-cho, Matsuyama, \\ Ehime 790-8578, Japan and ${ }^{2}$ Department of Pharmacognosy, College of Pharmaceutical Sciences, Matsuyama University, 4-2 Bunkyo-cho, \\ Matsuyama, Ehime 790-8578, Japan
}

(Received 2 October 2019; and accepted 13 October 2019)

\begin{abstract}
Caloric restriction (CR) is a major contributor to good health and longevity. CR mimetics (CRMs) are a group of plant-derived compounds capable of inducing the benefits of CR. Since a longevity gene, SIRT1, inhibits T-cell activation and SIRT1 loss results in increased T-cell activation, we hypothesized that compounds capable of activating SIRT1 signaling can inhibit T-cell activation and function as CRMs. Thus we propose, in the present study, the application of a T-cell activation-inhibitory assay to screen candidate CRMs. Well-known CRMs, such as resveratrol, butein, and fisetin, suppressed the anti-CD3/CD28 antibody-induced activation of mouse spleen T-cells. We next randomly assessed 68 plant-derived compounds for screening novel candidate CRMs using this bioassay and found that all four compounds showing $\mathrm{IC}_{50}$ values $<5 \mu \mathrm{M}$, such as curcumin, $\alpha$-mangostin, nobiletin, and heptamethoxyflavone, have beneficial functions for health such as anti-inflammatory effect. These results suggest that the T-cell activation-inhibitory assay can be used to screen candidate CRMs.
\end{abstract}

A caloric restriction (CR) value of $30-60 \%$ has been shown to effectively extend the life span of a variety of organisms by inducing good health (32). However, long-term CR remains a challenge to humans. A practical approach to overcoming this dilemma is developing CR mimetics (CRMs) capable of providing CR benefits without performing the actual CR. The concept of CRMs was first described by Lane et al. in 1998 (26). Ingram et al. (23) later argued that candidate CRMs should: (i) mimic the metabolic, hormonal, and physiological effects of CR; (ii) significantly reduce long-term food intake; (iii) activate CR-like stress response pathways and

Address correspondence to: Dr Mitsunari Nakajima, Matsuyama University, Department of Pharmaceutical Pharmacology, College of Pharmaceutical Sciences, 4-2 Bunkyo-cho, Matsuyama, Ehime 790-8578, Japan

Tel: +81-89-926-7069, Fax: +81-89-926-7162

E-mail: mnakajim@g.matsuyama-u.ac.jp provide protection against a variety of stressors; and (iv) produce CR-like effects on longevity, reduction of age-related diseases, and function maintenance. Several studies using microarray-based gene expression analysis have revealed that several medications modulating glucose and lipid metabolism and inflammation, could be potential candidates for CRMs $(10,14)$.

In genetic studies, Sir2 family genes of NAD ${ }^{+}$-dependent deacylases, sirtuins, were extensively studied as longevity genes in yeast $(3,22)$. Likewise, Sir2 and its orthologs have been proven essential for CR-mediated longevity in several organisms such as worms (51) and flies (44). Specifically, the mammalian Sir2 ortholog SIRT1 was studied in mice and found to regulate metabolic responses to nutritional cues $(13,46)$. For instance, SIRT1-deficient mice were metabolically unable to adapt to CR (4), indicating the importance of SIRT1 in the physiological response to CR. SIRT1 is expressed in various tissues 
of animals such as the brain, visceral fat pad, kidney, liver, and muscle $(5,9)$. Conversely, SIRT1-overexpressing mice showed significant protection against high-fat diet-induced adverse effects on glucose metabolism $(1,42)$, suggesting that SIRT1 improves metabolism regulation in mice.

Given that sirtuins affect the metabolic responses to $\mathrm{CR}$ and longevity, sirtuin-activating compounds were screened to identify candidate CRMs. Howitz et al. (21) and Milne et al. (33) developed in vitro screening systems for SIRT1-activating compounds and identified possible candidate CRMs including resveratrol and SRT1720. However, Pacholec et al. (37) reported that these compounds did not activate SIRT1 through native protein substrates. Another study has shown that these SIRT1 activators interact directly with SIRT1, activating it through an allosteric mechanism (12). Hence, to overcome these controversies, alternative screening systems with different concepts are required.

CRMs, such as resveratrol, butein, and fisetin, are well-known sirtuin-activating compounds and show growth-suppressive effects on various types of T-cells $(24,49,60)$. On the other hand, SIRT1 inhibits T-cell activation and SIRT1 loss results in increased T-cell activation (57). These evidences are indicative that compounds capable of activating SIRT1 or upstream/downstream SIRT1 signaling machineries can inhibit T-cell activation and function as CRMs. In the present study, we propose the application of a T-cell activation-inhibitory assay to screen candidate CRMs. We adopt a culture system for this bioassay using anti-CD3/CD28 antibody-induced T-cell activation (19). Initially, we examined the T-cell activation-inhibitory effect of already well-known CRMs, such as resveratrol, and then screened randomly 68 plant-derived compounds for possible CRMs.

\section{MATERIALS AND METHODS}

Animals. Female BALB/c mice were purchased (SLC, Shizuoka, Japan) at 6-weeks old, maintained under controlled temperature and light $\left(23^{\circ} \mathrm{C}\right.$ and 12-h light/dark, respectively) and used at 7-8-weeks old, while receiving food and water ad libitum. All experimental procedures followed the Guidelines for Animal Experimentation of the Animal Care and Use Committee of Matsuyama University (Matsuyama, Japan). The female mice were $6-9$ weeks old at the start of the experiments.

Spleen cell culture. To examine T-cell growth, single-cell suspensions were prepared by mincing mice spleen tissue, and passing them through a $40 \mu \mathrm{m}$ nylon mesh (Falcon, Corning, NY, USA). The cell suspensions were then treated with ACK lysis buffer $\left(0.15 \mathrm{M} \mathrm{NH}_{4} \mathrm{Cl}, 1 \mathrm{mM} \mathrm{KHCO}{ }_{3}\right.$, and $0.1 \mathrm{mM}$ $\mathrm{Na}_{2}$ EDTA) for $5 \mathrm{~min}$ and red blood cells were removed from the spleen cell suspensions. After washing with Hank's balanced salt solution (Thermo Fisher Scientific, Waltham, MA, USA), the resulting pellets were used as spleen leukocytes, including a few percent of T-cells. For the T-cell growth-inhibitory assay, the spleen leukocytes were stimulated with $1 \mu \mathrm{g} / \mathrm{mL}$ each of coated anti-CD3 (BioLegend, San Diego, CA, USA) and soluble anti-CD28 (BioLegend) antibodies for $48 \mathrm{~h}$ in the presence of assay samples. The assay was performed using culture medium containing indicated concentrations $(0-100 \mu \mathrm{M})$ of samples and/or $0.1 \%$ dimethyl sulfoxide (DMSO), and incubations were done at $37^{\circ} \mathrm{C}$, in a humidified atmosphere containing 5\% $\mathrm{CO}_{2}$. The culture medium contained $45 \mathrm{~mL}$ of RPMI 1640 (Thermo Fisher Scientific), $50 \mu \mathrm{L}$ of 2-mercaptoethanol (Thermo Fisher Scientific), $0.5 \mathrm{~mL}$ of penicillin/streptomycin/ glutamine (Thermo Fisher Scientific), and $5 \mathrm{~mL}$ of heat-inactivated fetal calf serum (FCS) (Thermo Fisher Scientific). To assess T-cell growth, we used a 3-(4,5-dimethylthiazol-2-yl)-2,5-diphenyltetrazolium bromide (MTT) cell proliferation kit (Roche, Basel, Switzerland), following the manufacturer's instructions. MTT is reduced to form purple formazan crystals in metabolically active cells. Thus, the appearance of formazan crystals suggests the existence of anti-CD3/CD28 antibody-activated T-cells in the spleen leukocyte cultures. The formazan crystals were solubilized with $78 \%$ DMSO-containing medium and the OD value $(570 / 655)$ was measured. We defined $\mathrm{IC}_{50}$ as concentrations of compounds to inhibit anti-CD3/CD28 antibody-induced T-cell activation by $50 \%$ on the OD value.

Mouse monocyte macrophage RAW264.7 culture. Mouse monocyte macrophage RAW264.7 cells were purchased from DS Pharma Biomedical (Osaka, Japan) and maintained in Dulbecco's modified Eagle's medium (DMEM) (Nacalai tesque, Kyoto, Japan) supplemented with $10 \%$ FCS and $0.1 \%$ penicillin/ streptomycin/glutamine (Thermo Fisher Scientific, San Diego, CA, USA).

Western Blot analyses. RAW264.7 cells were treated with/without samples at indicated concentrations. Three hours later, lipopolysaccharide (LPS; 0111E. coli B4, L2630; Sigma-Aldrich, St. Louis, MO, USA) was added to the culture at a concentration of 
$10 \mathrm{ng} / \mathrm{mL}$, and the cells were harvested $24 \mathrm{~h}$ later for Western blotting. Blots were probed with rabbit anti-Cox-2 (D5H5) (Cell Signaling \#12282, Tokyo, Japan), rabbit anti-SIRT1 (Cell Signaling \#2028), or rabbit anti-acetyl NF- $\mathrm{kB}$ p65 (Lys310; D2S3J) antibodies (Cell Signaling \#12629); all at 1 : 1000 dilutions, were detected with horse radish peroxidase (HRP)-conjugated anti-rabbit IgG antibody (Cell Signaling) and re-probed with HRP-conjugated anti-glyceraldehyde 3-phosphate dehydrogenase (G3PDH) antibody (Sigma-Aldrich) or HRP-conjugated anti- $\alpha$-tubulin (11H10) (Cell Signaling). Data are presented as the fold-change of control mean \pm SEM.

Assay samples. 3,5,6,7,8,3',4'-Heptamethoxyflavone (HMF) and nobiletin were generously provided by Ushio ChemiX (Omaezaki, Japan). Resveratrol and rapamycin (Sigma-Aldrich), SRT1720 (AdooQ, Irvine, CA, USA), fisetin (Cayman, Ann Arbor, MI, USA), butein and curcumin (Tokyo Chemical Industry, Tokyo, Japan), and $\alpha$-mangostin (Wako Pure Chemical Corporation, Osaka, Japan) were commercially obtained.

The 68 randomly screened samples were divided as follows: 18 flanovonoids (including nobiletin and HMF), 14 phenolics, 10 phenylpropanoids, 9 hydrolyzable tannins, 4 coumarins, 3 monoterpenes, 3 diarylheptanoids (including curcumin), 2 xanthones (including $\alpha$-mangostin), 2 chromones, a lignin, an alkaloid, and a hydroxyl acid.

Statistical analyses. Data are expressed as mean \pm standard error of the mean (SEM). The data were analyzed using one-factor analysis of variance followed by Tukey's multiple comparison test. $P<0.05$ was considered significant.

\section{RESULTS AND DISCUSSION}

To examine the effectiveness of our T-cell activation-inhibitory assay for the screening of candidate CRMs, we first assessed the effects of well-known CRMs, such as resveratrol, which is one of the most studied CRM, on mouse spleen T-cell activation (2, $12,21,33,39,40,50)$. Resveratrol inhibited anti-CD3/CD28 antibody-induced T-cell activation in the mouse spleen cultures $\left(\mathrm{IC}_{50}=12 \mu \mathrm{M}\right)$ (Figs. 1, 2, and 3). Other natural CRMs, such as butein and fisetin $(11,21,27,38,48,53,58,59)$, also inhibited T-cell activation $\left(\mathrm{IC}_{50}=2.8 \mu \mathrm{M}\right.$ and $5.2 \mu \mathrm{M}$, respectively) (Figs. 1 and 3). The synthetic CRM SRT1720 $(33,34)$ inhibited T-cell activation at a low concentration $\left(\mathrm{IC}_{50}=0.25 \mu \mathrm{M}\right)$ (Figs. 1 and 3). Rapamycin, a macrolide antibiotic, is known to inhibit the target of the rapamycin (TOR) signaling pathway and extend the lifespan of genetically heterogeneous mice $(20,47,52,54)$. Rapamycin was highly effective in inhibiting T-cell activation $\left(\mathrm{IC}_{50}=0.16 \mathrm{nM}\right)$ (Figs. 1 and 3).

Resveratrol, butein, fisetin, and SRT1720 are sirtuin activating compounds which have been reported to act as CRMs by inducing good health and/or longevity in some organisms $(15,21,25,53)$. It is still unclear if rapamycin affects sirtuin signaling. However, cross-reactions between sirtuin and TOR signaling have been reported $(18,56)$. These results suggest the possibility of the T-cell activation-inhibitory assay to screen candidate CRMs, even in the absence of a direct sirtuin-activating effect.

We equally performed preliminarily screens on candidate CRMs. Sixty-eight natural compounds, most of which were purified from a variety of plants (citrus, curcuma, and garcinia, amongst others), were assessed for their ability to inhibit anti-CD3/CD28 antibody-induced T-cell activation. A considerable number of compounds had substandard inhibitory effects $\left(\mathrm{IC}_{50}>50 \mu \mathrm{M}\right)$ on T-cell activation. Four compounds had $\mathrm{IC}_{50}$ values $<5 \mu \mathrm{M}$, while the $\mathrm{IC}_{50}$ values of some other 4 compounds were intermediate; 5-50 $\mu \mathrm{M}$ (Fig. 3). Three of the 4 active compounds $\left(\mathrm{IC}_{50}<5 \mu \mathrm{M}\right)$; curcumin $\left(\mathrm{IC}_{50}=2.2 \mu \mathrm{M}\right), \alpha$-mangostin $\left(\mathrm{IC}_{50}=1.2 \mu \mathrm{M}\right)$, and nobiletin $\left(\mathrm{IC}_{50}=0.9 \mu \mathrm{M}\right)$, are reported to have SIRT1-activating effects $(7,17,28$, 29, 41, 43, 55).

Another compound, $\mathrm{HMF}$ showing $\mathrm{IC}_{50}=1.0 \mu \mathrm{M}$, is reported to ameliorate brain and bone injuries (30, $31,35,36,45)$, and recently shown to possess anti-metabolic effects (16). However, HMF-induced SIRT1-related functions are yet to be reported. Thus, we performed detailed analysis concerning the relationship between HMF and SIRT1. The SIRT1 protein is associated with the RelA/p65 subunit of NF$\kappa \mathrm{B}$. The transcriptional activity of NF- $\mathrm{BB}$ is critical for the expression of inflammatory proteins such as cyclooxygenase-2 (Cox-2), and is known to be suppressed by deacetylation at the Lys 310 residue of its RelA/p65 subunit, mediated by the SIRT1 protein $(6,8)$. As shown in Fig. 4 A, HMF decreased LPSinduced Cox-2 expression in RAW264.7 macrophage-cells. We also observed an increase in SIRT1 expression, and the Lys 310 residue of the RelA/p65 subunit of NF- $\mathrm{KB}$ was deacetylated by HMF in the experimental condition (Fig. 4 B and C). These observations suggest that HMF activates SIRT1 signaling directly or indirectly, which causes suppressed activity of NF- $\mathrm{KB}$ by deacetylation of the RelA/p65 

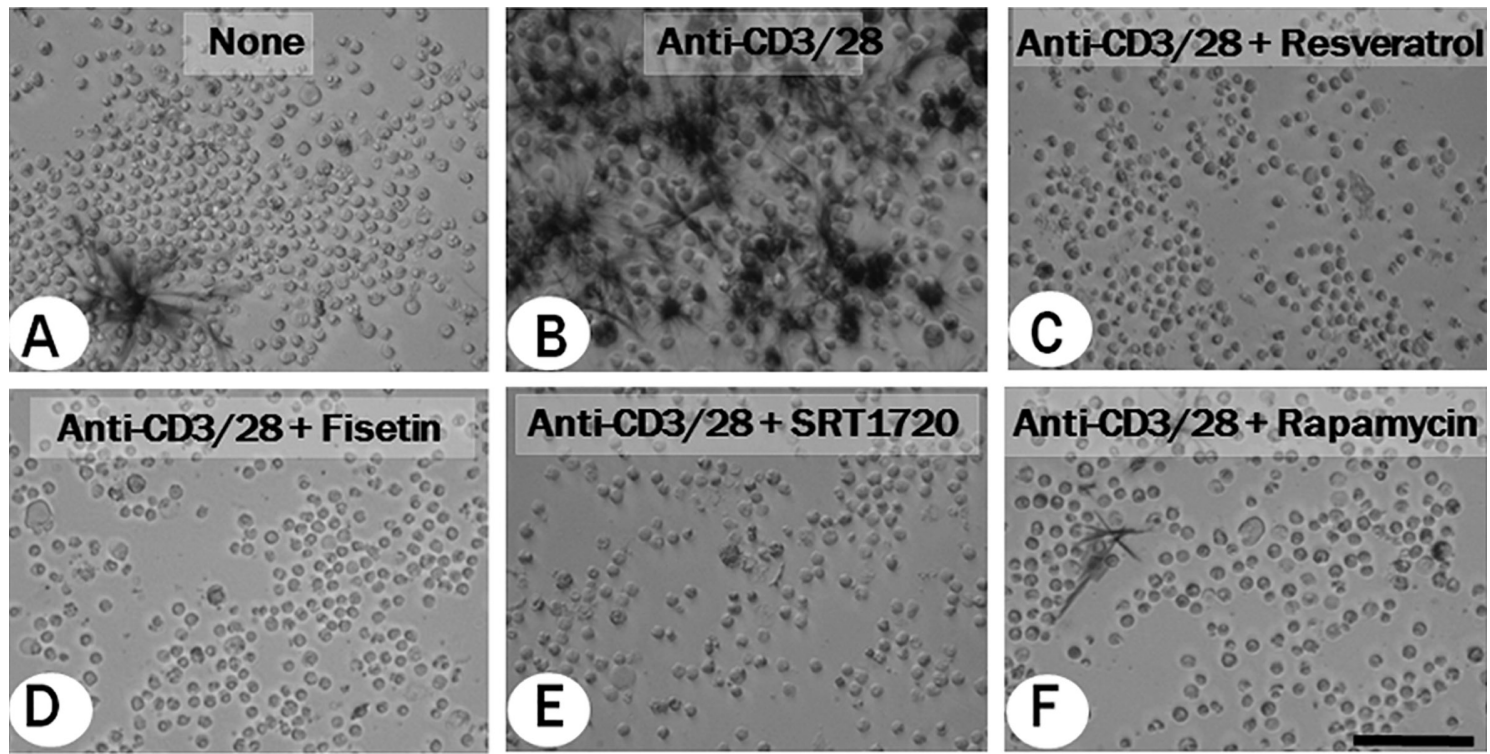

Fig. 1 Photos of the T-cell activation-inhibitory assay culture. Spleen leukocytes were stimulated with anti-CD3/CD28 antibodies for $48 \mathrm{~h}$ in the presence of assay samples. MTT was added to the culture and changed to purple formazan crystals in activated T-cells. (A) Neither sample nor antibody stimulation. (B) Sample absent, but antibody stimulation present. An enormous number of formazan crystals are visible. (C) Resveratrol $(50 \mu \mathrm{M})$ with antibody stimulation. (D) Fisetin (50 $\mu \mathrm{M})$

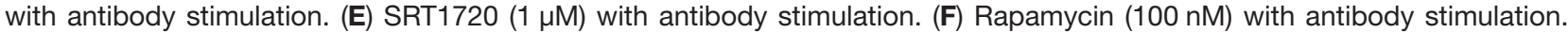
Small formazan crystals seen in $(A)$ and $(F)$ were sporadically observed. As these crystals are considered to be formed by macrophages which exist sporadically in the spleen leukocyte cultures, the influence to the assessment of $I_{50}$ of $C_{R M s}$ could be negligible. Bar $=50 \mu \mathrm{m}$.

subunit and reduced expression of Cox- 2 .

This study was prompted by research articles which indicate that well-known CRMs such as resveratrol, butein, and fisetin, are sirtuin-activating compounds and show growth-suppressive effects on a variety of T-cells $(24,49,60)$. Secondly another article indicated that SIRT1 was essential for maintaining T-cell tolerance (57). Overall, these articles are indicative of the fact that compounds that enhance SIRT1-signaling may suppress T-cell growth, though with poorly understood mechanisms. This implies that compounds directly activating SIRT1 or its upstream/downstream signaling machineries, may be screened as candidate CRMs by the T-cell activation-inhibitory assay.

The T-cell activation-inhibitory assay is a unique method for routine CRM screening. The assay 1) is very simple to perform, 2) can screen both direct SIRT1-activating compounds and indirect ones, 3) is sensitive and needs only minute sample quantities $(0.1 \mathrm{mg})$ for the screening procedure, and 4$)$ is a bioassay, as opposed to being an in vitro assay. This assay's specificity might be weak in some cases because it also detects compounds that suppress T-cell growth by modulating intracellular signaling pathways other than the SIRT1 signaling pathway. For

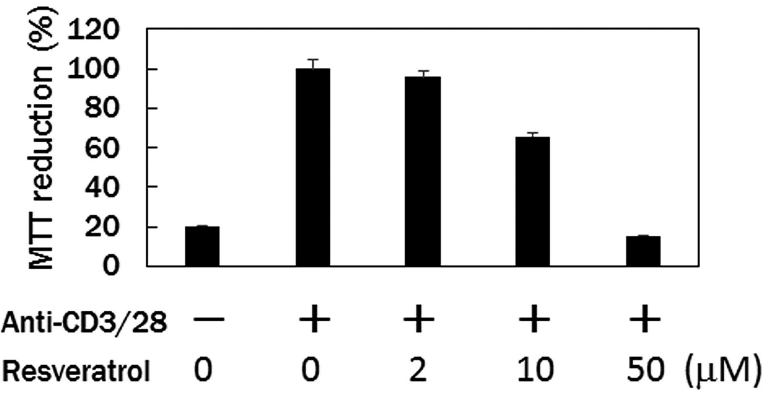

Fig. 2 Resveratrol inhibits anti-CD3/CD28 antibody-induced T-cell activation dose dependently. Spleen leukocytes were stimulated with anti-CD3/CD28 antibodies for $48 \mathrm{~h}$ in the presence of resveratrol at indicated concentrations, and the MTT assay performed.

example, cyclosporine, which impedes the calcineurin pathway, inhibits T-cell activation (19). Thus, additional steps, such as testing anti-inflammatory and/or anti-metabolic functions, could be used to exclude such mismatching compounds from the list of candidate CRMs. After getting the present study, we found an additional function of HMF in the early adipogenesis, which would be published elsewhere. 


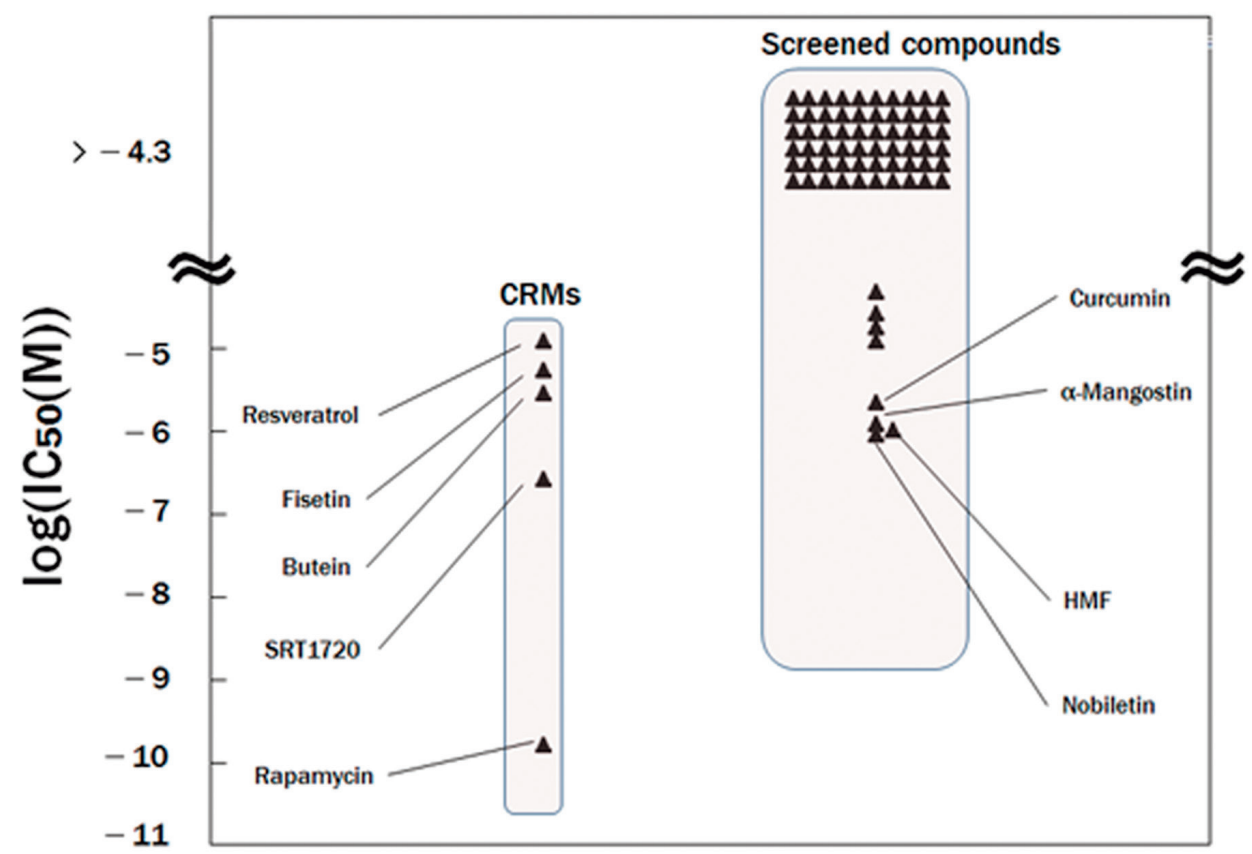

Fig. 3 Summary of the T-cell activation-inhibitory assay. Spleen leukocytes were stimulated with anti-CD3/CD28 antibodies for $48 \mathrm{~h}$ in the presence of a variety of samples, and the MTT assay was performed. The $I_{50}$ of the most studied CRMs: resveratrol, fisetin, butein, SRT1720, and rapamycin, are plotted on the left, and those of the randomly screened 68 compounds on the right.

A

Cox-2

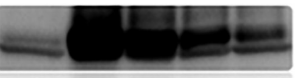

$\alpha-$-Tubulin

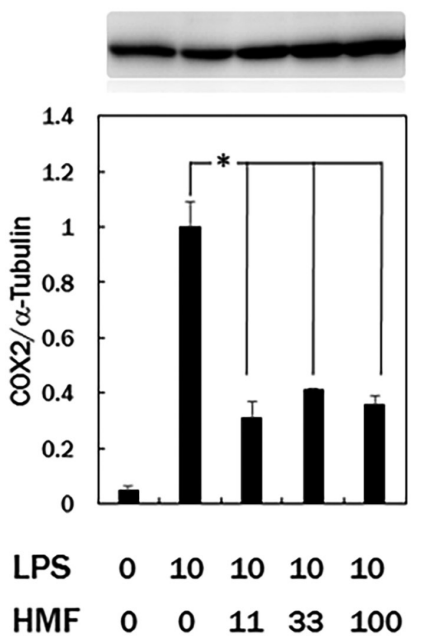

B

SIRT1

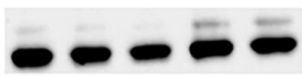

$\alpha$-Tubulin

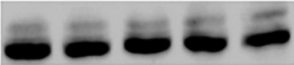

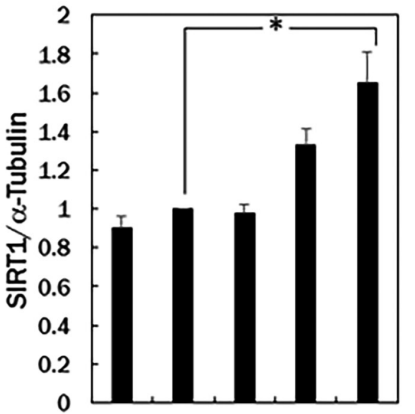

$\begin{array}{llllll}\text { LPS } & 0 & 10 & 10 & 10 & 10\end{array}$

HMF $\quad 0 \quad 0 \quad 1133 \quad 100$
C

Acetylated NF-kB

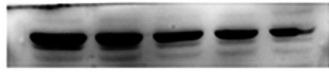

G3PDH
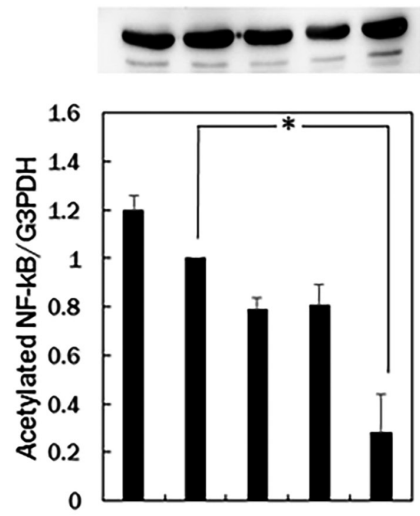

LPS $\quad \begin{array}{llllll}0 & 10 & 10 & 10 & 10 & (\mathrm{ng} / \mathrm{mL})\end{array}$

$\begin{array}{lllllll}\text { HMF } & 0 & 0 & 11 & 33 & 100 & (\mu \mathrm{M})\end{array}$

Fig. 4 HMF reduces Cox-2 expression, upregulates SIRT1 expression, and promotes deacetylation of the SIRT1 target, the RelA/p65 subunit of NF-KB. The expression of Cox-2, SIRT1, and the acetylated RelA/p65 subunit of NF- $K B$ in RAW264.7 macrophage cells were analyzed using Western blotting. (A) LPS-induced Cox-2 expression was reduced by HMF. (B) SIRT1 expression in the presence of LPS was upregulated by HMF. (C) Acetylation of the RelA/p65 subunit of NF- $K B$ in the presence of LPS was downregulated by HMF. Significant differences, compared to the HMF-untreated control are indicated with an asterisk. 


\section{CONFLICTS OF INTEREST}

The authors declare no conflicts of interest.

\section{Acknowledgements}

This work was supported by JSPS KAKENHI (grant Number, JP19K11707).

\section{REFERENCES}

1. Banks AS, Kon N, Knight C, Matsumoto M, Gutiérrez-Juárez $\mathrm{R}$, et al. (2008) SirT1 gain of function increases energy efficiency and prevents diabetes in mice. Cell Metab 8, 333341.

2. Baur JA, Pearson KJ, Price NL, Jamieson HA, Lerin C, et al. (2006) Resveratrol improves health and survival of mice on a high-calorie diet. Nature 444, 337-342.

3. Blander G and Guarente L (2004) The Sir2 family of protein deacetylases. Аnnu Rev Biochem 73, 417-435.

4. Boily G, Seifert EL, Bevilacqua L, He XH, Sabourin G, et al. (2008) SirT1 regulates energy metabolism and response to caloric restriction in mice. PLoS One 3, e1759.

5. Chen D, Bruno J, Easlon E, Lin SJ, Cheng HL, et al. (2008) Tissue-specific regulation of SIRT1 by calorie restriction. Genes Dev 22, 1753-1757.

6. Chen LF, Mu Y and Greene WC (2002) Acetylation of RelA at discrete sites regulates distinct nuclear functions of NF-kappaB. EMBO J 21, 6539-6548.

7. Choi YH, Bae JK, Chae HS, Kim YM, Sreymom Y, et al. (2015) $\alpha$-Mangostin regulates hepatic steatosis and obesity through SirT1-AMPK and PPAR $\gamma$ pathways in high-fat diet-induced obese mice. J Agric Food Chem 63, 8399-8406.

8. Chung S, Yao H, Caito S, Hwang JW, Arunachalam G, et al. (2010) Regulation of SIRT1 in cellular functions: role of polyphenols. Arch Biochem Biophys 501, 79-90.

9. Cohen HY, Miller C, Bitterman KJ, Wall NR, Hekking B, et al. (2004) Calorie restriction promotes mammalian cell survival by inducing the SIRT1 deacetylase. Science 305, 390 392.

10. Corton JC, Apte U, Anderson SP, Limaye P, Yoon L, et al. (2004) Mimetics of caloric restriction include agonists of lipid-activated nuclear receptors. J Biol Chem 279, 4620446212.

11. Currais A, Farrokhi C, Dargusch R, Armando A, Quehenberger $\mathrm{O}$, et al. (2018) Fisetin reduces the impact of aging on behavior and physiology in the rapidly aging SAMP8 mouse. $J$ Gerontol A Biol Sci Med Sci 73, 299-307.

12. Dai H, Kustigian L, Carney D, Case A, Considine T, et al. (2010) SIRT1 activation by small molecules: kinetic and biophysical evidence for direct interaction of enzyme and activator. J Biol Chem 285, 32695-32703.

13. Dali-Youcef N, Lagouge M, Froelich V, Koehl C, Schoonjans $\mathrm{K}$, et al. (2007) Sirtuins: the 'magnificent seven', function, metabolism and longevity. Ann Med 39, 335-345.

14. Dhahbi JM, Mote PL, Fahy GM and Spindler SR (2005) Identification of potential caloric restriction mimetics by microarray profiling. Physiol Genomics 23, 343-350.

15. Feige JN, Lagouge M, Canto C, Strehle A, Houten SM, et al. (2008) Specific SIRT1 activation mimics low energy levels and protects against diet-induced metabolic disorders by enhancing fat oxidation. Cell Metab 8, 347-358.
16. Feng K, Zhu X, Chen T, Peng B, Lu M, et al. (2019) Prevention of obesity and hyperlipidemia by heptamethoxyflavone in high-fat diet-induced rats. J Agric Food Chem 67, 2476-2489.

17. Franceschelli S, Pesce M, Ferrone A, Patruno A, Pasqualone L, et al. (2016) A novel biological role of $\alpha$-mangostin in modulating inflammatory response through the activation of SIRT-1 signaling pathway. $J$ Cell Physiol 231, 2439-2451.

18. Ghosh HS, McBurney M and Robbins PD (2010) SIRT1 negatively regulates the mammalian target of rapamycin. PLoS One 5, e9199.

19. Hamada Y, Nakajima M, Tsuzuki K, Amakura Y, Yoshimura M, et al. (2017) Heptamethoxyflavone reduces phosphodiesterase activity and T-cell growth in vitro. Int Arch Allergy Immunol 174, 113-120.

20. Harrison DE, Strong R, Sharp ZD, Nelson JF, Astle CM, et al. (2009) Rapamycin fed late in life extends lifespan in genetically heterogeneous mice. Nature 460, 392-395.

21. Howitz KT, Bitterman KJ, Cohen HY, Lamming DW, Lavu S, et al. (2003) Small molecule activators of sirtuins extend Saccharomyces cerevisiae lifespan. Nature 425, 191-196.

22. Imai S, Armstrong CM, Kaeberlein M and Guarente L (2000) Transcriptional silencing and longevity protein Sir2 is an NAD-dependent histone deacetylase. Nature 403, 795-800.

23. Ingram DK, Zhu M, Mamczarz J, Zou S, Lane MA, et al. (2006) Calorie restriction mimetics: an emerging research field. Aging Cell 5, 97-108.

24. Ishikawa C, Senba M and Mori N (2017) Butein inhibits NF$\kappa \mathrm{B}, \mathrm{AP}-1$ and Akt activation in adult T-cell leukemia/lymphoma. Int J Oncol 51, 633-643.

25. Lagouge M, Argmann C, Gerhart-Hines Z, Meziane H, Lerin C, et al. (2006) Resveratrol improves mitochondrial function and protects against metabolic disease by activating SIRT1 and PGC-1alpha. Cell 127, 1109-1122.

26. Lane MA, Ingram DK and Roth GS (1998) 2-Deoxy-d-glucose feeding in rats mimics physiologic effects of calorie restriction. J Anti Aging Med 1, 327-337.

27. Liou CJ, Wei CH, Chen YL, Cheng CY, Wang CL, et al. (2018) Fisetin protects against hepatic steatosis through regulation of the Sirt1/AMPK and fatty acid $\beta$-oxidation signaling pathway in high-fat diet-induced obese mice. Cell Physiol Biochem 49, 1870-1884.

28. Lone J, Parray HA and Yun JW (2018) Nobiletin induces brown adipocyte-like phenotype and ameliorates stress in 3T3-L1 adipocytes. Biochimie 146, 97-104.

29. Mariño G, Pietrocola F, Madeo F and Kroemer G (2014) Caloric restriction mimetics: natural/physiological pharmacological autophagy inducers. Autophagy 10, 1879-1882.

30. Matsumoto $\mathrm{C}$, Inoue $\mathrm{H}$, Tominari $\mathrm{T}$, Watanabe $\mathrm{K}$, Hirata $\mathrm{M}$, et al. (2015) Heptamethoxyflavone, a citrus flavonoid, suppresses inflammatory osteoclastogenesis and alveolar bone resorption. Biosci Biotechnol Biochem 79, 155-158.

31. Matsumoto S, Tominari T, Matsumoto C, Yoshinouchi S, Ichimaru R, et al. (2018) Effects of polymethoxyflavonoids on bone loss induced by estrogen deficiency and by LPSdependent inflammation in mice. Pharmaceuticals (Basel) 11, pii: E7.

32. Mercken EM, Carboneau BA, Krzysik-Walker SM and de Cabo R (2012) Of mice and men: the benefits of caloric restriction, exercise, and mimetics. Ageing Res Rev 11, 390398.

33. Milne JC, Lambert PD, Schenk S, Carney DP, Smith JJ, et al. (2007) Small molecule activators of SIRT1 as therapeutics for the treatment of type 2 diabetes. Nature 450, 712- 
716.

34. Minor RK, Baur JA, Gomes AP, Ward TM, Csiszar A, et al. (2011) SRT1720 improves survival and healthspan of obese mice. Sci Rep 1, 70.

35. Okuyama S, Miyoshi K, Tsumura Y, Amakura Y, Yoshimura M, et al. (2015) 3,5,6,7,8,3',4'-heptamethoxyflavone, a citrus polymethoxylated flavone, attenuates inflammation in the mouse hippocampus. Brain Sci 5, 118-129.

36. Okuyama S, Morita M, Miyoshi K, Nishigawa $\mathrm{Y}$, Kaji M, et al. (2014) 3,5,6,7,8,3',4'-Heptamethoxyflavone, a citrus flavonoid, on protection against memory impairment and neuronal cell death in a global cerebral ischemia mouse model. Neurochem Int 70, 30-38.

37. Pacholec M, Bleasdale JE, Chrunyk B, Cunningham D, Flynn D, et al. (2010) SRT1720, SRT2183, SRT1460, and resveratrol are not direct activators of SIRT1. J Biol Chem 285, 8340-8351.

38. Padmavathi G, Roy NK, Bordoloi D, Arfuso F, Mishra S, et al. (2017) Butein in health and disease: A comprehensive review. Phytomedicine 25, 118-127.

39. Park SJ, Ahmad F, Philp A, Baar K, Williams T, et al. (2012) Resveratrol ameliorates aging-related metabolic phenotypes by inhibiting cAMP phosphodiesterases. Cell 148, 421-433.

40. Pearson KJ, Baur JA, Lewis KN, Peshkin L, Price NL, et al. (2008) Resveratrol delays age-related deterioration and mimics transcriptional aspects of dietary restriction without extending life span. Cell Metab 8, 157-168.

41. Peng Z, Li X, Xing D, Du X, Wang Z, et al. (2018) Nobiletin alleviates palmitic acid-induced NLRP3 inflammasome activation in a sirtuin 1-dependent manner in AML-12 cells. Mol Med Rep 18, 5815-5822.

42. Pfluger PT, Herranz D, Velasco-Miguel S, Serrano M and Tschöp MH (2008) Sirt1 protects against high-fat diet-induced metabolic damage. Proc Natl Acad Sci USA 105, 9793-9798.

43. Qi G, Guo R, Tian H, Li L, Liu H, et al. (2018) Nobiletin protects against insulin resistance and disorders of lipid metabolism by reprogramming of circadian clock in hepatocytes. Biochim Biophys Acta Mol Cell Biol Lipids 1863, 549-562.

44. Rogina B and Helfand SL (2004) Sir2 mediates longevity in the fly through a pathway related to calorie restriction. Proc Natl Acad Sci USA 101, 15998-16003.

45. Sawamoto A, Okuyama S, Amakura Y, Yoshimura M, Yamada T, et al. (2017) 3,5,6,7,8,3',4'-Heptamethoxyflavone ameliorates depressive-like behavior and hippocampal neurochemical changes in chronic unpredictable mild stressed mice by regulating the brain-derived neurotrophic factor: Requirement for ERK activation. Int $J$ Mol Sci 18, pii: E2133.

46. Schwer B and Verdin E (2008) Conserved metabolic regulatory functions of sirtuins. Cell Metab 7, 104-112.

47. Selman C, Tullet JM, Wieser D, Irvine E, Lingard SJ, et al. (2009) Ribosomal protein S6 kinase 1 signaling regulates mammalian life span. Science 326, 140-144.

48. Singh S, Singh AK, Garg G and Rizvi SI (2018) Fisetin as a caloric restriction mimetic protects rat brain against aging induced oxidative stress, apoptosis and neurodegeneration. Life Sci 193, 171-179.

49. Song B, Guan S, Lu J, Chen Z, Huang G, et al. (2013) Suppressive effects of fisetin on mice $\mathrm{T}$ lymphocytes in vitro and in vivo. J Surg Res 185, 399-409.

50. Timmers S, Konings E, Bilet L, Houtkooper RH, van de Weijer T, et al. (2011) Calorie restriction-like effects of 30 days of resveratrol supplementation on energy metabolism and metabolic profile in obese humans. Cell Metab 14, 612622.

51. Wang Y and Tissenbaum HA (2006) Overlapping and distinct functions for a Caenorhabditis elegans SIR2 and DAF-16/ FOXO. Mech Ageing Dev 127, 48-56.

52. Weichhart T (2018) mTOR as regulator of lifespan, aging, and cellular senescence: A mini-review. Gerontology 64, 127134.

53. Wood JG, Rogina B, Lavu S, Howitz K, Helfand SL, et al. (2004) Sirtuin activators mimic caloric restriction and delay ageing in metazoans. Nature 430, 686-689. Erratum in: Nature 431, 107.

54. Yoo YJ, Kim H, Park SR and Yoon YJ (2017) An overview of rapamycin: from discovery to future perspectives. $J$ Ind Microbiol Biotechnol 44, 537-553.

55. Zendedel E, Butler AE, Atkin SL and Sahebkar A (2018) Impact of curcumin on sirtuins: A review. $J$ Cell Biochem 119, 10291-10300.

56. Zhang S, Cai G, Fu B, Feng Z, Ding R, et al. (2012) SIRT1 is required for the effects of rapamycin on high glucoseinducing mesangial cells senescence. Mech Ageing Dev 133, 387-400.

57. Zhang J, Lee SM, Shannon S, Gao B, Chen W, et al. (2009) The type III histone deacetylase Sirt1 is essential for maintenance of $\mathrm{T}$ cell tolerance in mice. $J$ Clin Invest 119, 30483058.

58. Zheng W, Feng Z, You S, Zhang H, Tao Z, et al. (2017) Fisetin inhibits IL-1 $\beta$-induced inflammatory response in human osteoarthritis chondrocytes through activating SIRT1 and attenuates the progression of osteoarthritis in mice. Int Immunopharmacol 45, 135-147.

59. Zhu Y, Wang K, Ma Z, Liu D, Yang Y, et al. (2019) SIRT1 activation by butein attenuates sepsis-induced brain injury in mice subjected to cecal ligation and puncture via alleviating inflammatory and oxidative stress. Toxicol Appl Pharmacol 363, 34-46.

60. Zou T, Yang Y, Xia F, Huang A, Gao X, et al. (2013) Resveratrol inhibits CD4+ T cell activation by enhancing the expression and activity of Sirt1. PLoS One 8, e75139. 